\title{
Supercritical Calorimetry: An Emerging Field
}

\author{
Frédéric Lavanchy, Sophie Fortini, and Thierry Meyer*
}

\begin{abstract}
Calorimetry (adiabatic, isothermal, differential, oscillating or acoustic) is generally based on heat-flow measurements of the studied system. Most of its applications are dedicated to kinetic-parameter determination, safety studies and process optimization, phase equilibrium and phase transition studies. Heat flow calorimetry on the lab scale is currently limited to low viscosity fluids. An emerging new field is concerned with the use of calorimetry in the presence of supercritical fluids as solvent reaction, which will be named supercritical calorimetry. Supercritical carbon dioxide $\left(\mathrm{CO}_{2} \mathrm{Sc}\right)$ represents an increasingly interesting media for a wide variety of reactions. To fulfill this need, a special supercritical calorimeter has been developed in collaboration with Mettler-Toledo, Schwerzenbach, $\mathrm{CH}$ and some preliminary results are presented.

This paper explores supercritical calorimetry applied to the intrinsic properties of carbon dioxide in the liquid, gas and especially supercritical phase as well as applications and theory related to reaction calorimetry. The $\mathrm{CO}_{2}$ sc heat capacity $\left(\mathrm{c}_{\mathrm{p}}\right)$ is measured over the range of $33-112^{\circ} \mathrm{C}$ and $77-206$ bar using a reaction calorimeter (RC1e, Mettler-Toledo) coupled with a high-pressure HP350 metallic reactor. Measured values are compared to theoretical values obtained from Wagner and Span's equation of state. 3D representations of the predicted values for heat capacity, density and sound speed of carbon dioxide in the fluid phase are presented.
\end{abstract}

Keywords: Equation of state · Heat capacity · Heat-flow calorimeter - Speed of sound ·

Supercritical calorimetry $\cdot$ Supercritical carbon dioxide

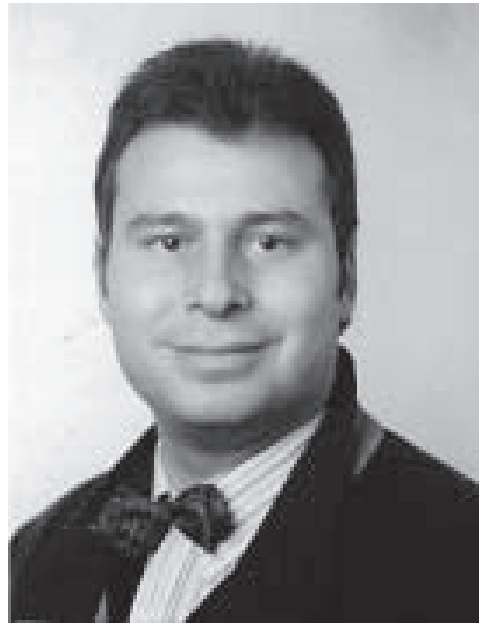

${ }^{*}$ Correspondence: MER Dr. T. Meyer Ecole Polytéchnique Fédérale de Lausanne Faculté des Sciences de Base Institut de Science des Procédés chimiques et biologiques

$\mathrm{CH}-1015$ Lausanne

Tel.: +41216933614

Fax: +41216933190

E-Mail: thierry.meyer@epfl.ch

http://dcwww.epfl.ch/lgrc

\section{Introduction}

Historically Denys Papin was the first researcher to find the critical point of water in a high-pressure vessel in 1680. The real interest in this 'peculiar state of matter' came directly after the discovery of Baron Charles Cagniard de LaTour, a French physicist, in the nineteenth century [1]. Step by step this 'new' state showed intrinsic properties situated between a liquid and a gas: such as solvent power and viscosity, both being closely related to the density. Some other properties of supercritical fluids, for example isobaric specific heat $\left(c_{p}\right)$, thermal conductivity and binary diffusion coefficients [2], have a more complex behavior with regards to pressure and temperature.

The advantages to be gained from carrying out reactions in SCFs, apart from the environmental aspect, can be listed as follows. Firstly, it allows a better phase behavior control to facilitate either homogenization or, on the contrary, reagent, product and solvent separation. Secondly, the increased diffusion coefficients can speed up the reaction rate, both homogeneous and heterogeneous, when diffusion is a controlling factor. Thirdly, there is an enhanced control of the operating conditions, through both pressure and temperature, which can improve the control of reaction pathways and product selectivity.

The peak for industrial applications of supercritical carbon dioxide was reached in 1975 with the extraction of caffeine from green coffee beans. At this point some of the characteristic advantages from using supercritical carbon dioxide emerged. The first deals with safety reasons: $\mathrm{CO}_{2} \mathrm{sc}$ is non-toxic, non-flammable and environmentally friendly. The second concerns process reasons: $\mathrm{CO}_{2} \mathrm{Sc}$ could easily be separated from products, has low viscosity, high diffusion rate, adjustable solvent power and finally is inexpensive, with carbon dioxide waste production from other processes being recycled [3]. The critical temperature of $31.1^{\circ} \mathrm{C}\left(\mathrm{T}_{\mathrm{c}}\right)$ and pressure of $73.8 \mathrm{bar}\left(\mathrm{P}_{\mathrm{c}}\right)$ are easily accessible. For chemical reasons, $\mathrm{CO}_{2} \mathrm{sc}$ has a high miscibility with gases such as hydrogen and has some short-range inhomogeneities around dissolved solutes that could lead to reaction speed enhancement as showed by Brenneke and Chateauneuf [4]. The 'green' solvent aspect is a major interest as the 
replacement of chlorinated or other harmful liquid solvents has great public impact. The coupling of this last effect with savings in expensive separating costs could overcome the induced investments in high-pressure equipment and operating costs.

Supercritical carbon dioxide as the reaction solvent has its limitations. Even with tunable solvent power, at high density it behaves as a rather poor solvent, like liquid hydrocarbon solvents, for small molecules, especially the polar ones. For high molecular mass molecules, polymers for example, the solvent power of $\mathrm{CO}_{2} \mathrm{Sc}$ is extremely poor. An exception are the fluorinated polymers for which homogeneous polymerization processes are feasible [5][6].

The field of calorimetry is based on the measurement of heat flow and finds most of its applications in the determination of kinetic parameters, safety studies and process optimization [7], phase equilibrium and phase transition studies [8]. The different methods can be divided according to the following criteria [9]: size of the sample, measurement sensibility, heat-balance or heat-flow strategy [10], differential principle. A summary of this classification for major calorimetric methods is given in the Table.

There are diverse applications of calorimetry in the context of supercritical fluids, but no application could be found in the literature that reported calorimetric studies of reactions. Former applications of calorimetry to supercritical state were restricted mainly to high-pressure flow calorimetry for the study of energetic interactions of molecules and especially excess enthalpies of mixing [11] as well as pure enthalpy and specific heat capac-
Fig. 1. The 1 liter HP350 metallic reactor from Mettler-Toledo AG.

Table. Classification of principal calorimetric methods.

\begin{tabular}{llll} 
Method & Measurement principles & Utilization field & Sample size \\
\hline $\begin{array}{l}\text { Differential scanning } \\
\text { calorimetry (DSC) }\end{array}$ & $\begin{array}{l}\text { Differential, ideal } \\
\text { flow or isoperibolic }\end{array}$ & $\begin{array}{l}\text { Screening, } \\
\text { decompositions }\end{array}$ & $1-50 \mathrm{mg}$ \\
$\begin{array}{l}\text { Accelerating rate } \\
\text { calorimetry (ARC) }\end{array}$ & Ideal accumulation & Decompositions & $0.5-3 \mathrm{~g}$ \\
$\begin{array}{l}\text { Reaction calorimetry } \\
\text { (RC) }\end{array}$ & Ideal flow & Reactions & $300-2000 \mathrm{~g}$ \\
\hline $\begin{array}{l}\text { Dewar } \\
\text { Calvet calorimeter }\end{array}$ & Differential, ideal flow & $\begin{array}{l}\text { Reactions and } \\
\text { decompositions }\end{array}$ & $0.5-3 \mathrm{~g}$ \\
\hline & & $\begin{array}{l}\text { Reactions and } \\
\text { thermal stability }\end{array}$ & $100-1000 \mathrm{~g}$ \\
\hline
\end{tabular}

ity $c_{p}$ measurements [12-14]. The instruments used are, to large extent, micro calorimeters where differential scanning calorimetry (DSC) is strongly represented and also to a lesser extent Calvet calorimeters and flow calorimeters. The development of supercritical calorimetry in a batch high-pressure reactor is fundamental for the study of $\mathrm{CO}_{2} \mathrm{sc}$ behavior and its direct implications on specific reactions [15]. It also represents an opportunity for process safety analysis involving such a medium. Another advantage concerns the possibility of coupling the reaction calorimeter with additional analytic sensors such as ultrasonic, FTIR, and $\mathrm{pH}$ probes, leading to more accurate reaction understanding.

\section{Experimental Section}

\subsection{RC1e Calorimeter and HP350 High-pressure Reactor}

The supercritical calorimeter (determined total volume of $1.1641 \pm 0.002 \mathrm{l}$ ) has been developed in collaboration with Mettler-Toledo AG, and the reactor is presented in Fig. 1. The maximum operating pressure and temperature are 350 bar and $300{ }^{\circ} \mathrm{C}$. The reactor is equipped with a magnetic drive, pitch blade turbine, $25 \mathrm{~W}$ calibration heater, PT100 temperature sensor and a pressure sensor. All the necessary measurements as well as process and control variables are monitored and controlled using WinRC2000 ${ }^{\circledR}$ software.

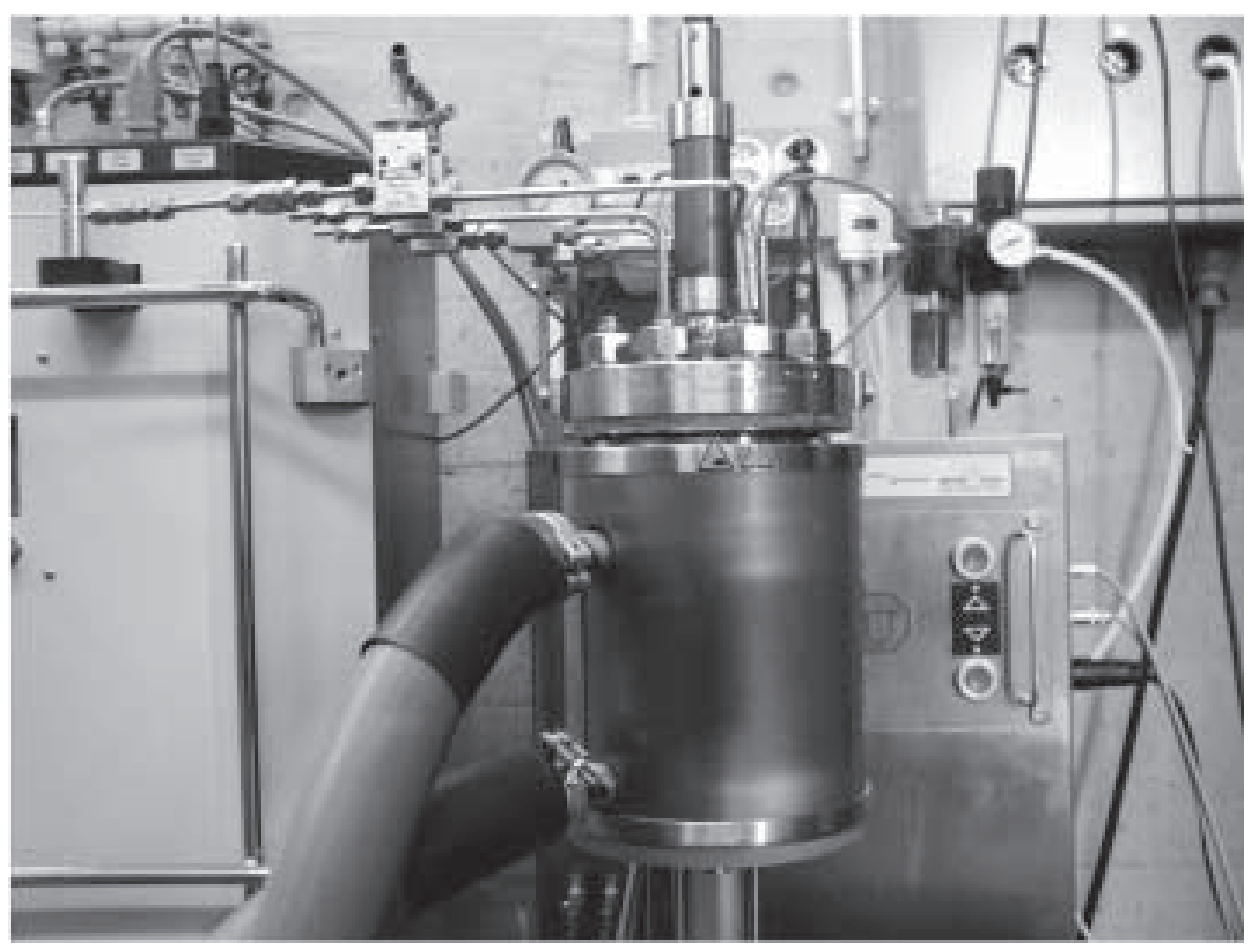




\section{2. $\mathrm{CO}_{2}$ Feed}

The carbon dioxide bottle is equipped with a dip tube to allow liquid $\mathrm{CO}_{2}$ to be pumped out. The bottle is mounted on a balance with an extended precision of $\pm 0.1 \mathrm{~g}$ over the range of $0-12.8 \mathrm{~kg}$. The pressure inside the bottle is 49.5 bar and the $\mathrm{CO}_{2}$ purity is better than $99.9 \%$ $\left(\mathrm{CO}_{2} 30\right.$ quality).

\section{Theoretical Section}

\subsection{Supercritical Fluids}

The supercritical region is defined as the state of a compound, mixture or element above its critical pressure $\left(\mathrm{P}_{\mathrm{c}}\right)$ and critical temperature $\left(\mathrm{T}_{\mathrm{c}}\right)$ but below the pressure required to condense it into a solid [1]. The critical point corresponds to the end of the vapor-liquid coexistence curve. As shown in Fig. 2, the supercritical domain is delimited by the isobar and isotherm from the critical point, and the sublimation curve on the upper part. For $\mathrm{CO}_{2}$ the critical temperature and pressure are $31.1{ }^{\circ} \mathrm{C}$ and 73.8 bar. It appears clearly that for pressures up to 6000 bars it could be possible to condense $\mathrm{CO}_{2}$ from the supercritical to the solid state. Supercritical fluids (SCF) are neither vapor nor liquids but physically correspond to the convergence of the two mediums. For a pure compound, there is only one critical pressure $P_{c}$ and temperature $T_{c}$ as well as one critical density $d_{c}$, which is defined as the average of vapor and liquid phase densities at the critical point. These allow the pure compound state to be characterized with reduced values defined as follows:

$$
T_{r}=T / T_{c} \quad P_{r}=P / P_{c} \quad d_{r}=d / d_{c}
$$

where $T_{r}, P_{r}$ and $d_{r}$ are the reduced temperature, pressure and density.

\subsection{Equation of State}

The ability to describe the phase behavior of a media such as supercritical carbon dioxide, would allow its intrinsic properties to be predicted directly for process optimization purposes. Many equations of state are adapted to classical phase characterization but most of them fail to describe fluids at high pressure. For them, simple equations of state such as ideal gas, virial, cubic and van der Waals need to be modified to account for special effects, especially near the critical point. Examples of modified cubic equations of state are the famous RedlichKwong and Peng-Robinson ones, which are able to describe single-component as well as multi-component systems [16]. The most common methods to treat supercritical fluids are based on the following strategies: treatment as a dense gas (cubic equations of state, perturbation equations, lattice gas and scaling forms), as an expanded liquid, empirically or with the mixing rule. More details of these methods can be found in Brennecke and Eckert [17].

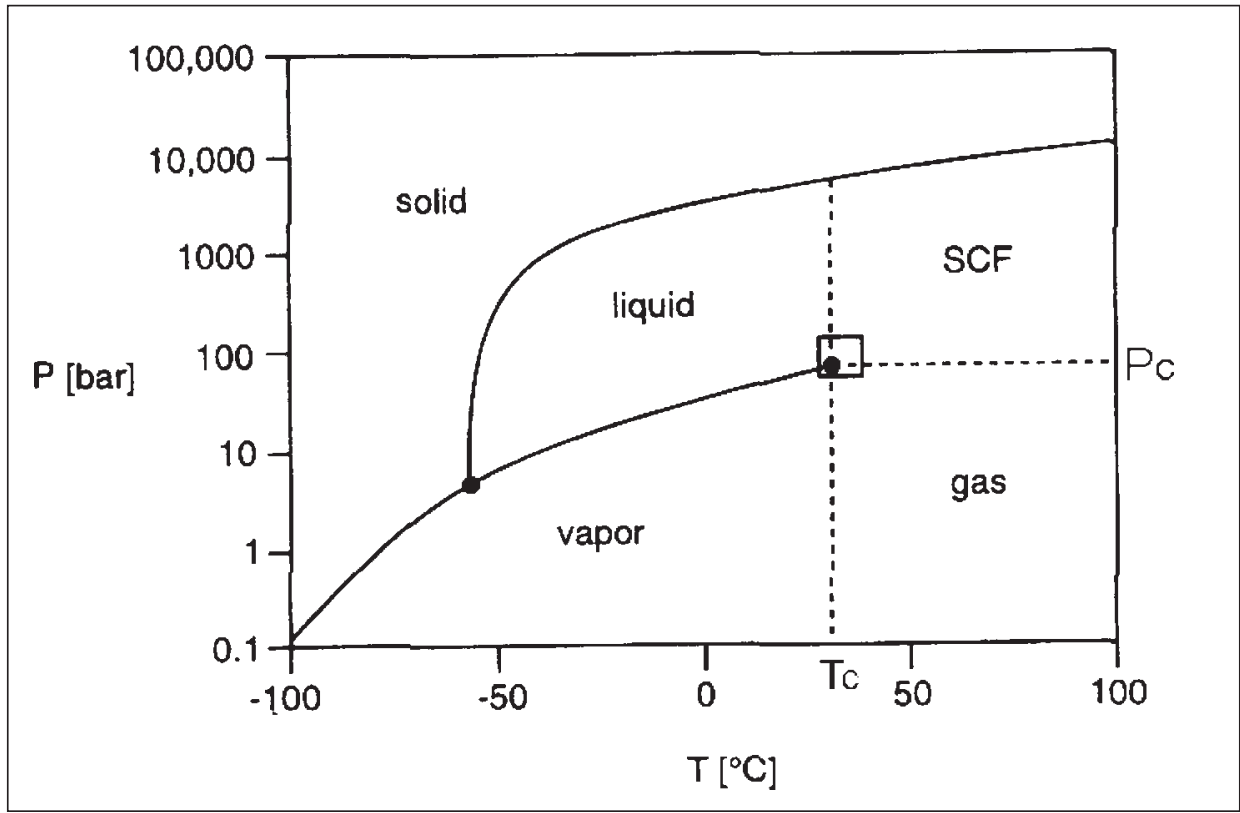

In this paper Wagner and Span's equation of state [18] was chosen for the following reasons: it is restricted to carbon dioxide and results in data compilation up to 1996. The final fundamental equation form is explicit in the dimensionless Helmholtz free energy $\phi=\mathrm{A} /(\mathrm{RT})$ with an ideal gas part $\phi^{O}$ and residual part $\phi^{r}$.

$$
\phi\left(d_{r}, \tau\right)=\phi^{0}\left(d_{r}, \tau\right)+\phi^{r}\left(d_{r}, \tau\right)
$$

where $d_{r}$ is the reduced density and $\tau=$ $\mathrm{T}_{\mathrm{c}} / \mathrm{T}=1 / \mathrm{T}_{\mathrm{r}}$ the inverse reduced temperature.

With the Helmholtz energy as a function of temperature and density being one form of a fundamental equation, all thermodynamic properties of pure $\mathrm{CO}_{2}$ could be obtained through complex treatment of the residual Helmholtz part.

Finally, the residual part of the Helmholtz energy as well as all its temperature and density derivatives are expressed in simple but excessively heavy sums of coefficients obtained from the correlations of these functions with respect to the experimental data. For a fixed temperature and density, accessible properties are in particular the pressure $\mathrm{P}$, the isobaric heat capacity $c_{p}$ and the sound velocity $u_{s}$ (Eqn. 3-5). As an example one of the expressions of the derivatives of the Helmholtz energy with reduced density $\phi_{d}^{r}$ is given (Eqn. 6), it uses other derivatives and functions also expressed by a sum of coefficients. One of them is the exponential function $\psi$ (Eqn. 7). The complete set of equations can be found in Wagner and Span [18]. 


$$
\begin{aligned}
& P\left(d_{r}, \tau\right)=d R T \cdot\left(1+d_{r} \cdot \phi_{d_{r}}^{r}\right) \\
& c_{p}\left(d_{r}, \tau\right)=R \cdot\left(-\tau^{2}\left(\phi_{\tau \tau}^{0}+\phi_{\tau \tau}^{r}\right)+\frac{\left(1+d_{r} \phi_{d_{r}}^{r}-d_{r} \tau \phi_{d_{t, \tau}}^{r}\right)^{2}}{1+2 d_{r} \phi_{S}^{r}+d_{r}^{2} \phi_{d_{r} d_{r}}^{r}}\right) \\
& c_{s}^{2}\left(d_{r}, \tau\right)=R T \cdot\left(1+2 d_{r} \phi_{d_{r}}^{r}+d_{r}^{2} \phi_{d_{r}, d_{r}}^{r}-\frac{\left(1+d_{r}-d_{r} \tau \phi_{d_{r} \tau}^{r}\right)^{2}}{\tau^{2}\left(\phi_{r \tau}^{0}+\phi_{r t}^{r}\right)}\right)
\end{aligned}
$$

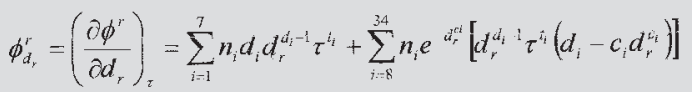

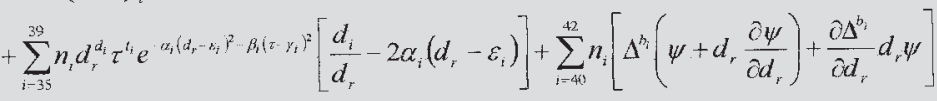

$$
\begin{aligned}
& \psi=e^{\left.-C_{i}\left(d_{r}-1\right)^{2}-D_{i}(2-1)\right)^{2}}
\end{aligned}
$$

$\mathrm{R}$ is the specific gas constant, $\phi_{k j}^{0}$ the derivatives of the ideal-gas part of the dimensionless Helmholtz energy, $\phi_{k_{7}}^{r}$ the derivatives of the residual part of dimensionless Helmholtz energy, $\mathrm{k}$ and $\mathrm{j}$ being either $d_{r}$ and/or $\tau$ leading to first or second derivatives, $\Delta$ the distance function, $\mathrm{n}_{\mathrm{i}}, \mathrm{d}_{\mathrm{i}}, \mathrm{t}_{\mathrm{i}}, \mathrm{c}_{\mathrm{i}}, \varepsilon_{\mathrm{i}}, \gamma_{\mathrm{i}}, \alpha_{\mathrm{i}}, \beta_{\mathrm{i}}, \mathrm{C}_{\mathrm{i}}, \mathrm{D}_{\mathrm{i}}$ are constants with i known values.

The covered region of temperature and pressure is of great interest as the one close to the critical point is also considered with estimated uncertainty for each property.

\section{Results and Discussion}

For a pure compound, the phase changes from liquid to vapor are accompanied by abrupt changes in properties and thermodynamic values such as enthalpy, molar volume and entropy. Isobaric specific heat goes to 'infinity' at the phase transition: all the heat brought to the system is used for vaporization and no temperature change occurs. This phase transition corresponds to a first order transition with respects to the Ehrenfest classification.

At the critical point, the isothermal compressibility $\kappa_{T}$ rises to 'infinity' as the slope of the pressure against molar volume is equal to zero (Eqn. 8).

Fig. 3. A. 3D view of a P-T-d phase diagram for $\mathrm{CO}_{2}$. B. P-T plot for $\mathrm{CO}_{2}$.

A

B $\left.(\partial P / \partial V)_{T}\right|_{T c, P c} \equiv 0$

$\kappa_{T}=-1 /\left.V \cdot(\partial P / \partial V)_{T} \equiv \infty\right|_{T c, P c}$

The variation of the thermodynamic properties through a phase change to the supercritical state is greatly dependent on the original state. Transition from liquid, vapor or liquid-vapor to the supercritical phase exhibits different property evolutions. This kind of phase transition looks like second-order one with respect to the Ehrenfest classification, but isochoric heat capacity $\mathrm{c}_{\mathrm{v}}$ clearly shows $\lambda$-transition [18].

Fig. 3A, 4A, and 5A represent the modeled (Matlab ${ }^{\circledR}$ ) evolution, according to Wagner and Span's EOS, of density, sound speed and isobaric heat capacity respectively versus pressure and temperature in a $3 \mathrm{D}$ plot. Scattering at the domain boundaries is due to interpolation meshing. Fig. 4B, 5B and 6B are the corresponding $2 \mathrm{D}$ plots for a $446.7 \mathrm{~kg} / \mathrm{m}^{3}$ density according to experiment. ty evolution of the three fluid phases along with pressure and temperature. The blank surface between the boundary of the liquid and gas phases is the coexistence zone where the two phases are at
Fig. 3A gives a good idea of the densi-
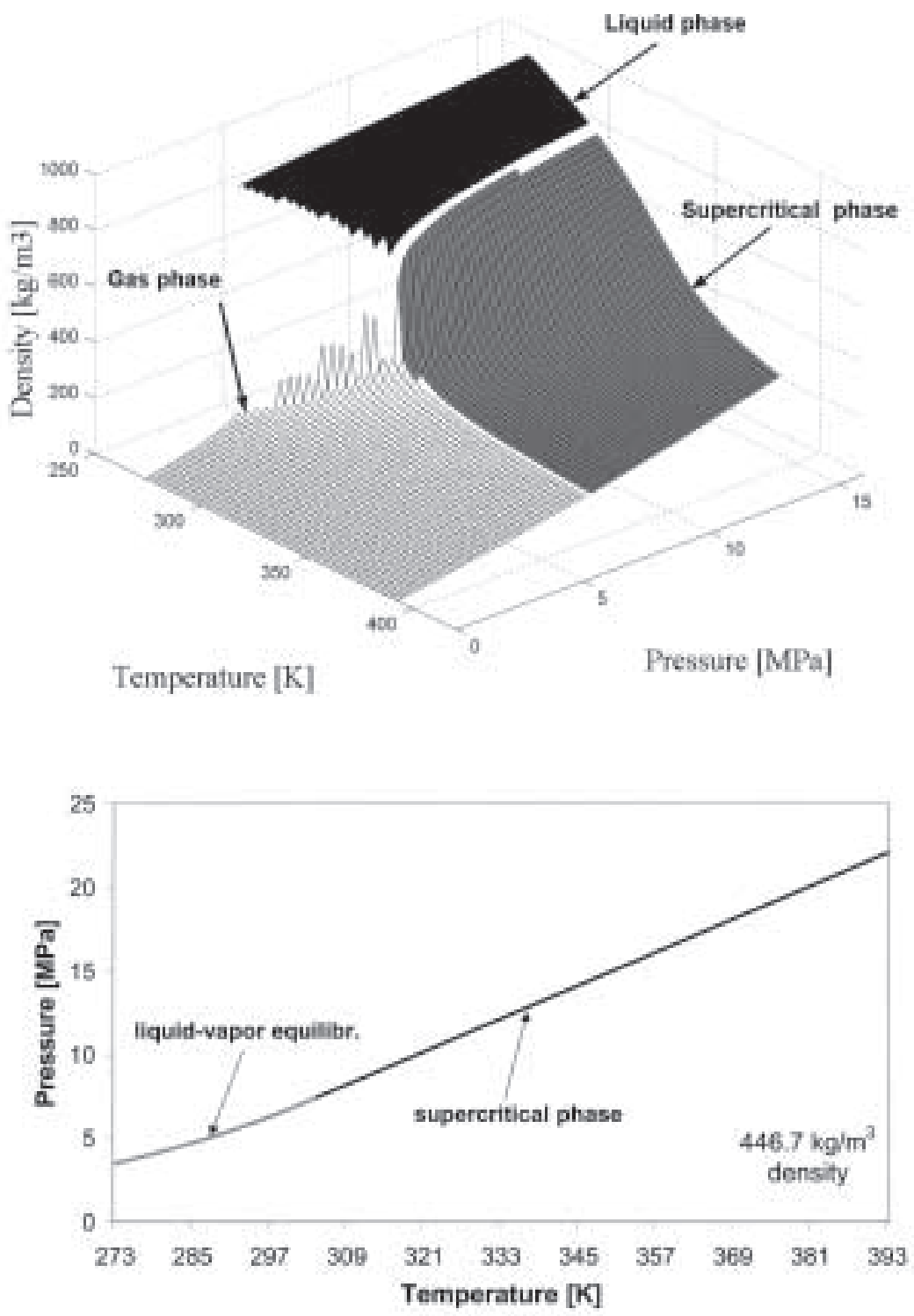


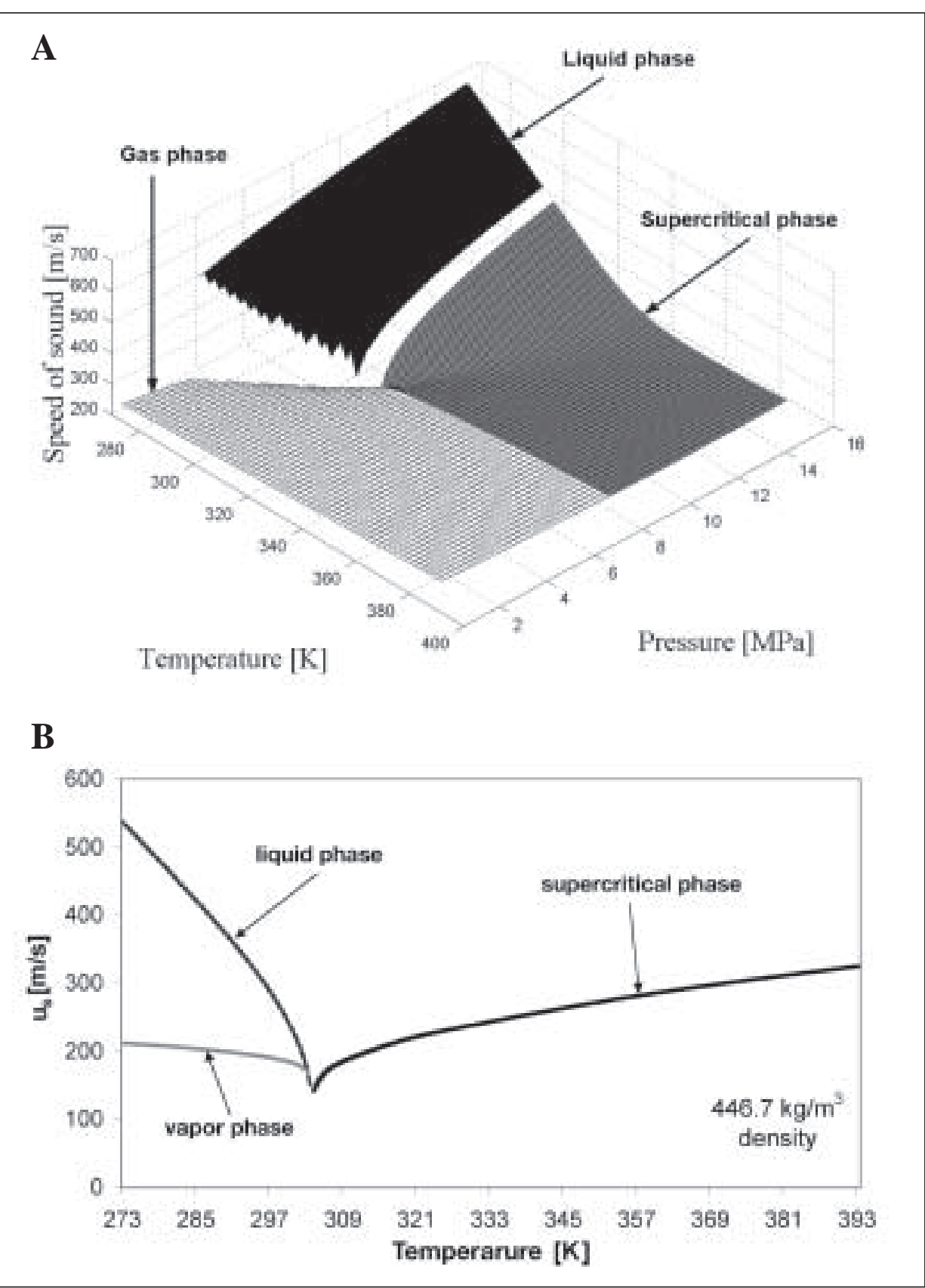

equilibrium, its P-T projection representing the vaporization line. The gas and liquid densities converge close to the critical point, where by definition, density equals the critical density value. In the supercritical phase, a small rise of the temperature lowers the density value from the 'liquid' one to the gaseous one along isobars, the slope becoming steeper closer to the critical point. Fig. 3B shows the correspondent pressure increase with temperature from the liquid-vapor system to the supercritical phase at a density of $446.7 \mathrm{~kg} / \mathrm{m}^{3}$. The sound speed evolution of carbon dioxide with pressure and temperature is depicted in Fig. 4A. Its comparison with the preceding Fig. 3A clearly shows the behavior similarity of density and sound speed. For the three phases an increase of the pressure leads to higher density and also higher sound ence between the two plots is around the critical point. As sound speed is directly related to density but also to adiabatic compressibility $\kappa_{\mathrm{S}}$ (Eqn. 9) at the critical point, the first being finite and the second one tending to infinity as it is proportional to isothermal compressibility, the sound speed is minimal, leading to the 'fall down' visible on Fig, 4A and 4B.

$$
u_{s}^{2}=\frac{1}{d \cdot \kappa_{s}} \quad \kappa_{s}=-\frac{1}{V}\left(\frac{\partial V}{\partial P}\right)_{s}
$$

The 'jump-effect' for $c_{p}$ values at the critical point following the liquid-vapor equilibrium could be observed in Fig. 5A. This could go over $500 \mathrm{~J} / \mathrm{kg} \cdot \mathrm{K}$, typical liquid and gas and supercritical values being usually less than $10 \mathrm{~J} / \mathrm{kg} \cdot \mathrm{K}$. speed along isotherms. The main differ-
Fig. 4. A. 3D view of a $\mathrm{P}-\mathrm{T}-\mathrm{u}_{\mathrm{s}}$ phase diagram for $\mathrm{CO}_{2}$. B. $\mathrm{u}_{\mathrm{s}}-\mathrm{T}$ plot for $\mathrm{CO}_{2}$. Liquid and vapor phases are at equilibrium.
Pure gas-supercritical phase or liquid-supercritical phase isochoric transition does not lead to such characteristic jumps as the enthalpy is continuous as well as its differentiability with respect to temperature. The $c_{p}$ values maximum rise is around the critical temperature (Fig. 5B) as the enthalpy of vapor and liquid at equilibrium are converging steeply at the critical temperature to reach the final enthalpy value of supercritical phase at this point.

The supercritical carbon dioxide $c_{p}$ values (Fig. 5B) were experimentally obtained through an internal temperature ramp of $0.3{ }^{\circ} \mathrm{C} / \mathrm{min}$. In the range of 60 $110{ }^{\circ} \mathrm{C}$ the experimental values are in good agreement with the theoretical ones, but from 31.5 to $60{ }^{\circ} \mathrm{C}$ they failed to describe the great 'jump' predicted by 


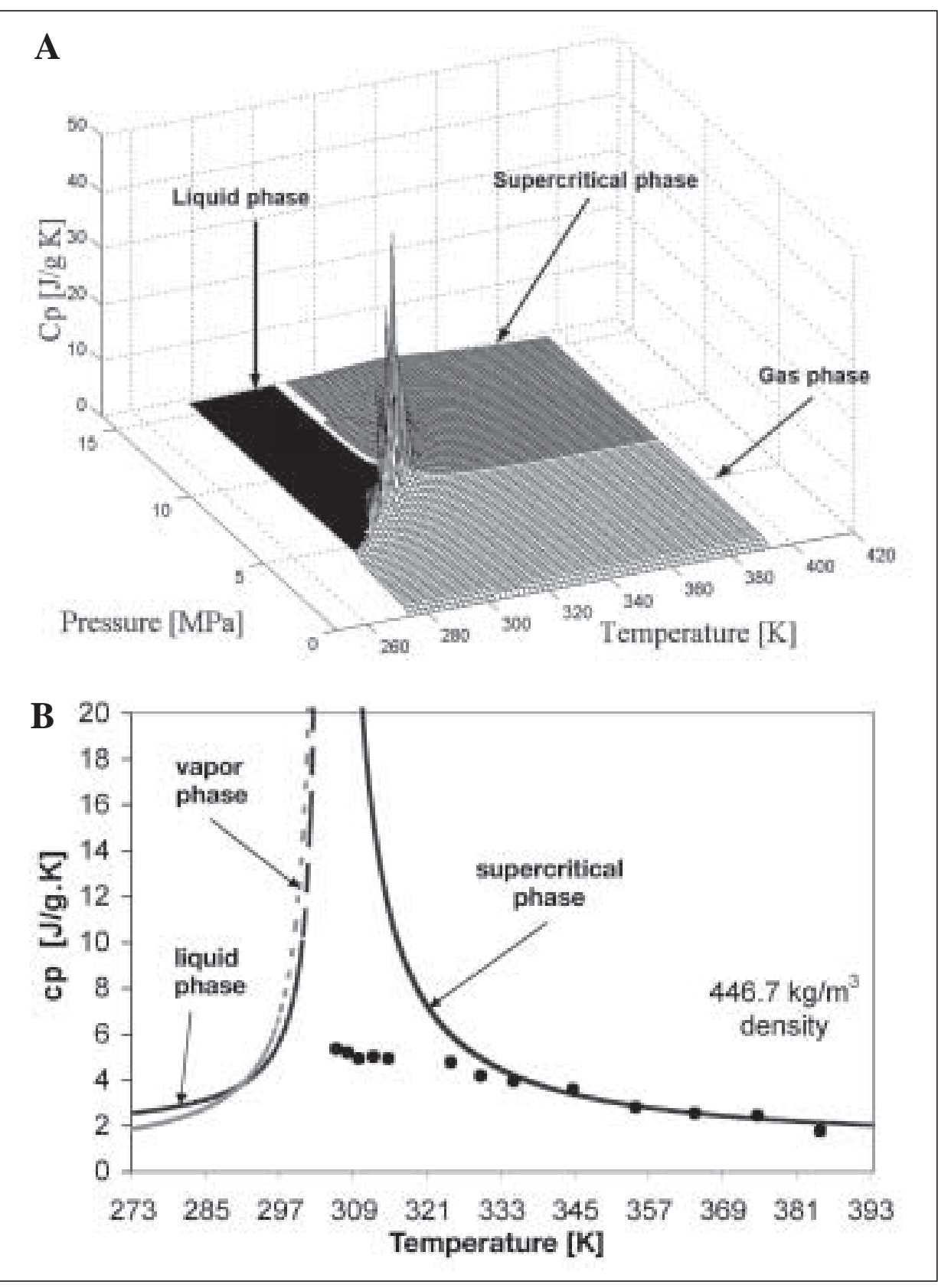

theory, especially just around the critical point. For this special region, the system's algorithms have to be improved with local heat transfer coefficients.

\section{Conclusions}

A special supercritical calorimeter has been developed in collaboration with Mettler-Toledo AG. The first results with supercritical carbon dioxide showed the great influence of local heat transfer coefficients that have to be taken into account. The system succeeds in measuring isobaric specific heat capacity showing an increase near the critical point. This opens the door to fundamental calorimetric study of reactions in supercritical phase.

\section{Acknowledgements}

The 'Fonds National Suisse pour la Recherche' is gratefully acknowledged for its financial support.

Received: February 19, 2002

[1] P.G. Jessop, W. Leitner, 'Chemical Synthesis Using Supercritical Fluids', WileyVCH, Weinheim, 1999.

[2] E. Kiran, P.G. Debenedetti, C.J. Peters, 'Supercritical Fluids: Fundamentals and Applications', Applied Sciences, vol. 366, 2000.

[3] M.A. Abraham, A.K. Sunol, 'Supercritical Fluids: Extraction and Pollution Prevention', ACS Symposium Series, vol. 670, 1996.

[4] J.F. Brenneke, E. Chateauneuf, Chem. Rev. 1999, 99, 433.

[5] J.L. Kendal, D.A. Canelas, J.L. Young, J.M. DeSimone, Chem. Rev. 1999, 99, 543.
Fig. 5. A. 3D view of a P-T- $C_{p}$ phase diagram for $\mathrm{CO}_{2}$. B. $\mathrm{C}_{\mathrm{p}}-\mathrm{T}$ plot for $\mathrm{CO}_{2}$ with experimental data. Liquid and vapor phases are at equilibrium.

[6] A.D. Shine, 'Polymers and Supercritical Fluids', Phys. Prop. Polym. Handb., Ed. J.E. Mark, Woodbury, New-York, 1996, p. 249.

[7] W. Regenass, J. Thermal Anal. 1997, 49, 1661.

[8] H.F. Ferguson, D.J. Frurip, A.J. Pastor, L.M. Peerey, L.F. Whiting, Thermochim. Acta 2000, 363, 1.

[9] F. Stoessel, 'Sécurité des procédés', polycopié de cours, EPFL, 1999.

[10] P.E. Meier, 'Reaktionskalorimetrie vom Feinsten', CIT Plus, 2001, p. 30.

[11] J.A.R. Renuncio, A. Cabañas, C. Pando, Pure Appl. Chem. 1999, 71(7), 1197.

[12] L.B. Koppel, J.M. Smith, J. Chem. Eng. Data 1960, 437.

[13] R. Bender, K. Bier, G. Maurer, Ber. Bunsenges. Phys. Chem. 1981, 85, 778.

[14] G. Ernst, G. Maurer, E. Wiederuh, J. Chem. Thermodynamics 1989, 21, 53.

[15] M. Poliakoff, M.W. George, S.M. Howdle, V.N. Bagratashvili, B.X. Han, H.K. Yan, Chinese J. Chem. 1999, 17(3), 212.

[16] E. Kiran, J.F. Brennecke, 'Current State of Supercritical Fluid Science and Technology', ACS Symposium Series, vol. 514, 1993, p. 1.

[17] J.F. Brennecke, C.A. Eckert, AICHE Journal 1989, 35(9), 1409.

[18] R. Span, W. Wagner, J. Phys. Chem. Ref. Data 1996, 25(6), 1509. 